Istanbul Finance Congress, November 5-6, 2020

\title{
MACHINE LEARNING AND ECONOMICS: BIBLIOMETRIC ANALYSIS
}

\author{
DOI: 10.17261/Pressacademia.2020. \\ PAP- V.12-2020(31)-p.104
}

Ebru Caglayan Akay ${ }^{1}$, N. Tuba Yilmaz Soydan ${ }^{2}$, Burcu Kocarik Gacar ${ }^{3}$

${ }^{1}$ Marmara University, Department of Econometrics, İstanbul, Turkey. ecaglayan@marmara.edu.tr, ORCID: 0000-0002-9998-5334

${ }^{2}$ Marmara University, Department of Econometrics, ìstanbul, Turkey. tuba.yilmaz@marmara.edu.tr,ORCID: 0000-0002-4009-9047

${ }^{3}$ Dokuz Eylül University, Department of Econometrics, İzmir, Turkey. burcukocarik@gmail.com, ORCID: 0000-0001-5944-4456

\section{To cite this document}

Caglayan Akay, E., Yilmaz Soydan, N.T., Kocarik Gacar, B., (2020). Machine learning and economics: bibliyometric analysis. PressAcademia Procedia (PAP), V.12, p.104

Permanent link to this document: http://doi.org/10.17261/Pressacademia.2020.1367

Copyright: Published by PressAcademia and limited licensed re-use rights only.

\section{ABSTRACT}

Purpose- The purpose of the study, is to examine the development of international studies on machine learning in the field of economics and econometrics using Bibliometric Analysis and to visualize by Social Network Analysis between 2010 and 2019 in the Web of Science database.

Methodology- Bibliometric Analysis is used to gather information about a discipline and to measure scientific productivity and progress. Social network analysis shows the relationship structure by visualizing the findings obtained as a result of bibliometric analysis.

Findings- As a result of the bibliometric analysis, findings were obtained on the basis of variables such as the changes in the studies on the basis of years, the most published authors and the most cited studies, the distribution of these studies by countries and institutions, the course of the study topic, and the progress in the relational formation in the keywords. In addition, with the Social Network Analysis, the authors that network with each other and clusters and relationships between countries and keywords were mapped.

Conclusion- When the findings were examined, it was determined that the most studies on these topics were conducted in the United States of America in each year and the most cited study was Varian (2014). At the same time, when the studies are evaluated in the last decade, it has been observed that the tendency towards the subjects of Machine learning, which attracts attention in Economics and Econometrics, has increased rapidly. It has been observed that the studies are associated with the keywords "causality" and "causal effect" as well as "Financial Econometrics", "Behavioral Economics", "Experimental Economics". The findings obtained shed light on the development of Machine Learning in the fields of Economics and Econometrics.

Keywords: Machine learning, economics, econometrics, bibliometric analysis, social network analysis JEL Codes: $\mathrm{C} 45, \mathrm{~A} 1, \mathrm{C} 1$

\section{MAKINE ÖĞRENMESI VE EKONOMI: BIBLLIYOMETRIK ANALIZ}

\begin{abstract}
ÖZET
Amaç- Bu çalışmada 2010 - 2019 yılları arasındaki son on yıllık süreçte Web of Science veri tabanında ekonomi ve ekonometri alanında makine öğrenmesi üzerine yapılan uluslararası nitelikteki çalışmaların ilgili literatürdeki gelişimi Bibliyometrik Analiz ile incelenmiştir. Ardından elde edilen bulgular Sosyal Ağ Analizi uygulanarak görselleştirilmiştir.

Metodoloji- Bibliyometrik Analiz, bir disiplin hakkında bilgi toplamak; bilimsel verimliliğin ve gelişimin ölçülmesi amacıyla kullanılmaktadır. Sosyal ağ analizi ise bibliyometrik analiz sonucunda elde edilen bulguları görselleştirerek, aralarındaki ilişki yapısını göstermektedir. Bulgular- Bibliyometrik Analiz sonucunda, yıllar bazında çalışmalarda meydana gelen değişimler, ilgili konu hakkında en çok yayın yapan yazar ve en fazla atıf alan çalışmalar, bu çalışmaların ülkeler ve kurumlara göre dağılımı, çalışma konusunun seyri ve anahtar kelimelerdeki ilişkisel oluşumdaki ilerlemeler gibi değişkenler temelinde bulgular elde edilmiştir. Ayrıca Sosyal Ağ Analizi ile birbirleriyle ağ yapısı oluşturan yazarlar, ülkeler ve anahtar kelimeler arasındaki kümelenmeler ve ilişkiler haritalandırılmıştır.

Sonuç- Bulgular incelendiğinde, bu konular üzerine her yıl en fazla çalışmanın Amerika Birleşik Devletlerinde yapıldığı, en çok atıf alan çalışmanın Varian (2014) olduğu belirlenmiştir. Aynı zamanda, son on yıldaki çalışmalar değerlendirildiğinde, Ekonomi ve Ekonometri'de günümüzde dikkat çeken Makine öğrenmesi konularına yönelimin hızla artmış olduğu, çalışmaların "nedensellik" ve "nedensel etki" anahtar kelimelerinin yanısıra "Finansal Ekonometri", "Davranışsal Ekonomi", "Deneysel Ekonomi" ile de ilișkilendirildiği ve finans ile bağlantılı anahtar kelimelerin sıklıkla kullanıldığı gözlemlenmiştir. Sonuçta elde edilen bulgular Makine Öğrenmesi'nin Ekonomi ve Ekonometri alanlarındaki gelişimine ışık tutar niteliktedir.
\end{abstract}

Anahtar Kelimeler: Makine öğrenmesi, ekonomi, ekonometri, bibliyometrik analiz, sosyal ağ analizi JEL Kodları: C45, A1, C1 


\section{Gíriş}

Zaman içinde internet teknolojilerinde meydana gelen gelişmeler önce bilimsel, ardından toplumsal hayatta ilerleme oluşturmaktadır. Makine öğrenmesi, temelde verinin sınıflandırılması ile bilgi elde edilmesini sağlayan algoritma temelli bir yaklaşımdır (Gürsakal, 2018).

Biyoloji, genetik, astronomi gibi farklı disiplinlerde sıklıkla kullanılan Makine öğrenmesinin Ekonomi ve Ekonometri disiplini içinde yerini alması oldukça yenidir (Çağlayan Akay, 2018 ve 2020). Makine öğrenmesi ve onun multidisipliner alanlarla bağlantısına olan ilginin akademik alanda da artmış olması bu konunun Ekonomi disipliniyle bağlantısının sorgulanmasına ve bu kapsamda Ekonometri alanında makine öğrenmesinin araştırılmasına yol gösterici olmuştur. Bu çalışmada, farklı bilim dallarında yaygın olarak kullanılmakta olan makine öğrenmesinin ekonomi ve ekonometri alanındaki yeri görülmek istenmiş ve makine öğrenmesi üzerine yayınlanan akademik çalışmaların son on yıllık gelişiminin bibliyometrik analiz ile incelenmesi amaçlanmıştır. Literatür incelendiğinde büyük veri ve makine öğrenmesi konularının bibliyometrik analizinin yapıldığı az sayıda çalışma olduğu görülmektedir. Bu çalışmalardan bazıları büyük veri ile ilgili çalışmaları ele alırken (Mishra (2013), Xian ve Madhavan (2014), Kocarık (2018), Liao vd. (2018), Ardito (2019), Liu vd. (2019), Rialti vd. (2019), Yilmazel (2019)) bazısı büyük veri ve makine öğrenmesi bir arada (Belmonte vd. (2020)) kullanmıştır. Bazıları başta sağlık olmak üzere çeşitli alanlarda makine öğrenmesi kullanımı (Makawana ve Jhaveri (2017), Stout vd. (2018), Bhattacharya (2019), dos Santos vd. (2019), Salod ve Singh (2020), Wang vd. (2020)), bazısı da yapay zeka (Alonso vd. (2018)) veya derin öğrenme (Li vd. (2020)) üzerine odaklanmıştır. Bu çalışmanın literatürdeki diğer çalışmalardan farkı, makine öğrenmesinin ekonomi ve ekonometri gibi spesifik bir alanda kullanımını incelemesidir. Bu amaçla öncelikle, uluslararası literatürde yapıımış olan çalışmaların derlenmesi ile araştırmanın veri seti elde edilmiştir. Bibliyometrik veriye, Sosyal Ağ Analizi uygulanarak çalışma bulguları değerlendirilmiştir.

\section{VERI ve METODOLOJi}

Bibliyometri, kitap (biblio) ve ölçüm bilimi (metric) sözcüklerinin birleşiminden oluşan bir kelimedir (Basaglia, 2014). Bilimsel yayın sayısı ve atıflardaki artış, projelere verilen destek miktarındaki artış, yapılan araştırma geliştirme faaliyetlerinin hızla ilerlemesi gibi niceliksel ve niteliksel argümanlar bir ülkedeki bilimsel ilerlemeyi göstermektedir. Bu nedenle belirli bir çalışma konusu hakkında yapılan istatistiksel tabanlı Bibliyometrik Analizler, çıktıların niceliklerinden yola çıkarak niteliklerine ulaşılabilecek pek çok etmeni inceleyerek bilimsel ilerleme hakkında bilgi verici nitelikte olmaktadır. Bu sayede bibliyometrik değerlendirmeler bir konudaki en verimli çalışmaları ve araştırmacıları belirlenirken hem de bunlar arasındaki etkileşimlerin boyutlarını gösterdiği için bilim dünyasına ve ülkelere bilimsel çalışmaların geleceği hakkında yön veren araştırmalardır (Pritchard, 1967; Al, 2008). Bibliyometrik Analiz ile yapılan çalışmaların sayısı, en çok atıf alan çalışmalar ve yazarlar, kullanılan anahtar kelimelerin gelişimi, konu hakkında en çok çalışma yapılan ülke veya destekleyen kurum ve kuruluş gibi bilgiler toplanabilmektedir. Bu anlamda kitap, dergi, makale ve bildiri sayısının belirlenerek ülke, zaman ve alan boyutunda sınıflandırılması durumunda betimleyici; alanyazının parçaları arasında kurulan ilişkileri ortaya çıkaran referanslar, atıf alan yazarlar gibi konularda yapıldığında değerlendirici bibliyometri olduğu ifade edilebilir (Nicholas and Ritchie, 1978). Bibliyometrik analizle elde edilen verilerin, bibliyometrik bilimsel haritalandırma yöntemi ile görselleştirilerek sunulması sonuçların değerlendirilmesi açısından avantaj sağlamaktadır. Bu noktada verilere Sosyal Ağ Analizi uygulamak amacı ile kullanılan bir çok farklı yazılım bulunmakla birlikte bu araştırma kapsamında VOSViewer programı kullanılmıştır.

Ağ, "sistemi oluşturan parçaların karşııklı etkileşimi ile beliren karmaşık sistemleri göstermenin paradigmatik bir yolu" olarak ifade edilmektedir (Toroczkai, 2005). Sosyal Ağ Analizi, Ağ bilimi içerisinde yer almakta olup insanlar veya aktörler aralarındaki iş ortaklığı ve arkadaşlık gibi sosyal bağlardan oluşan ilişki yapılarını ortaya koymaktadır. Böylece Sosyal Ağ Analizi, incelenen birimlerin birbirleriyle ilişkisini görsel sunumlarla ortaya çıkarmaya yardımcı olmaktadır. Bunun sonucunda ise bir konu hakkında çalışma yapmak isteyen araştırmacılara bir yol gösterebilmektedir. Bu çalışmada 2010 - 2019 yılları arasında Ekonomi ve Makine öğrenmesi ile Ekonometri ve Makine öğrenmesi konularında yapılan ve ISI tarafından sağlanan Web of Sciences (WoS) veri tabanı kullanılarak uluslararası dizinde taranan 311 çalışma derlenmiş ve Bibliyometrik Analiz ile incelenmiştir. Her üç kelimenin ortak olarak kullanıldığı 12 çalışma bulunmakta olup tekrar eden çalışmalar veri setinden çıkartılmıştır. Bu çalışmaların 178 tanesi makale, 117 tanesi bildiri, 11 tanesi kitap bölümü şeklindedir.

\section{BULGULAR}

Çalışmada anahtar kelimelerin kullanımı, yıllar bazında yapılan yayın sayıları, en çok yayın yapılan ülke ve atıf sayıları, yazarların yayın ve atıf sayısı, en çok yayın yapan ve atıf alan kurumlar ve ülkeleri ile bu konuda en çok yayın yapan dergiler incelenmiş ve elde edilen bulgular tartışılmıştır.

\section{Şekil 1: Yıllar Bazında Yapılan Yayın Sayıları Grafiğ}

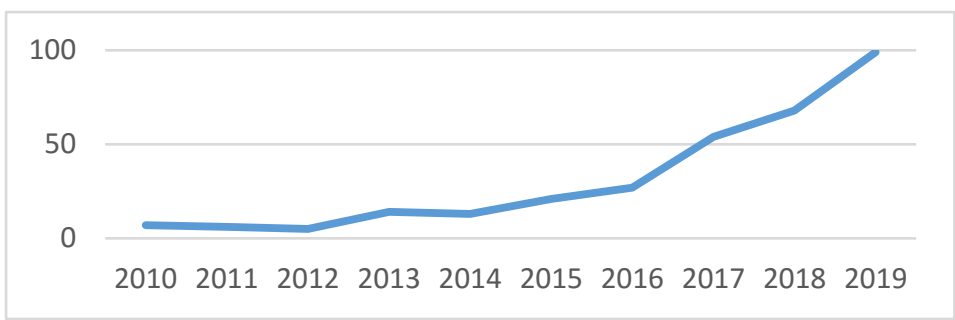

Şekil 1'de görülebileceği gibi Makine Öğrenmesinin Ekonomi ve Ekonometri alanında kullanımı 2015 (21) yılından itibaren artış göstermektedir. Son on yıl içerisinde yapılan 311 çalışmanın yaklaşık \%14'ü bu yıla kadar yapılmışken, kalan kısım bu yıldan sonraki çalışmaları oluşturmaktadır. Özellikle son yıllarda katlanarak artan yayın sayısı 2019 yılında 99'a ulaşmıştır. 
Tablo 1: Yıllara Göre Anahtar Kelimelerin Kullanımı

\begin{tabular}{|c|c|c|c|}
\hline Yıllar & En Çok Kullanılan Anahtar Kelimeler & Sıklık (Sırasıyla) & Makine Öğrenmesiyle Kümelenme \\
\hline 2010 & Metin Madenciliği, Proses Endüstrisi & 2,2 & - \\
\hline 2011 & Ekonomi, Makine Öğrenmesi, Algoritma & $3,3,2$ & Ekonometri, Markov Koşulu, Nedensellik \\
\hline 2012 & Makine Öğrenmesi & 2 & $\begin{array}{l}\text { Finansal Tahmin, Optimizasyon, Kredi Risk Analizi, Veri } \\
\text { Madenciliği }\end{array}$ \\
\hline 2013 & Ekonomi, Makine Öğrenmesi, Algoritma & $2,2,2$ & Sosyal Öğrenme, Deneysel Ekonomi, Zaman Serisi Analizi \\
\hline 2014 & Ekonomi, Makine Öğrenmesi & 2,2 & Stok Fiyat Tahmini, Algoritmik Ticaret, \\
\hline 2015 & Makine Öğrenmesi, Veri Madenciliği & 6,3 & $\begin{array}{l}\text { Politik Ekonomi, Finansal Regülasyon, Büyük Veri, Program } \\
\text { Değerlendirmesi }\end{array}$ \\
\hline 2016 & Makine Öğrenmesi, Büyük Veri, Ekonomi, Duyarlılık Analizi & $12,4,2,2$ & Büyük Veri, Biyoinformatik, Epistemoloji, \\
\hline 2017 & $\begin{array}{l}\text { Makine Öğrenmesi, Yapay Zeka, Tahmin, Büyük Veri, Vektör } \\
\text { Makineleri Destekleme, Oyun Teorisi, Davranışsal Ekonomi, }\end{array}$ & $20,4,3,3,2,2,2,2$ & $\begin{array}{l}\text { Büyük Veri, Oyun Teorisi, Davranışsal Ekonomi, Yapay Zeka, } \\
\text { Tahmin, Ekonometri, Ekonomi, }\end{array}$ \\
\hline 2018 & $\begin{array}{l}\text { Makine Öğrenmesi, Yapay Zeka, Ekonometri, Ekonomi, Büyük } \\
\text { Veri, Veri Bilimi, Optimizasyon, Veri Madenciliği, Yapay Sinir } \\
\text { Ağları, Derin Öğrenme }\end{array}$ & $31,6,5,4,4,4,3,3,2,2,2$ & Sosyal Medya, Stok Market Tahmini, Duygu Analizi \\
\hline 2019 & $\begin{array}{l}\text { Makine Öğrenmesi, Yapay Zeka, Büyük Veri, Derin Öğrenme, } \\
\text { Ekonometri, Algoritma, Sınıflandırma, Veri Bilimi, Yapay Sinir } \\
\text { Ağları, Davranışsal Ekonomi, Veri Madenciliği, Sosyal Medya }\end{array}$ & $44,9,9,9,7,4,3,3,3,2,2,2,2,2$ & $\begin{array}{l}\text { Ekonomi, Ekonometri, Derin Öğrenme, Yapay Zeka, } \\
\text { Tahmin, Nedensellik, Algoritma, Büyük Veri }\end{array}$ \\
\hline
\end{tabular}

Ağları, Davranışsal Ekonomi, Veri Madenciliği, Sosyal Medya

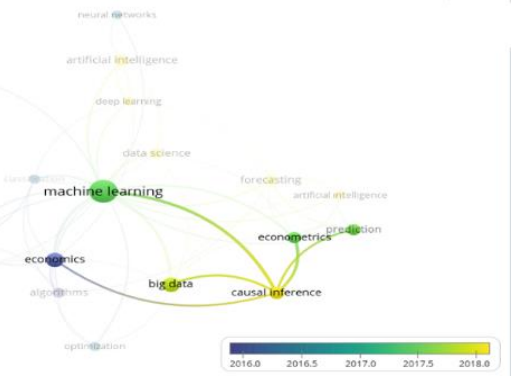

Şekil 2: Nedensellik ilişkisi

Tablo 1'de son on yıllık dönemde ilgili konuda yayınlanan çalışmalar incelendiğinde; 2010 yılında "Makine Öğrenmesi" anahtar kelimesi sadece bir kez kullanılmışken ve 2015 yılına kadar da kullanımı yaygın değilken, 2015 senesinde bu sayı üç katına çıkmış ve 2016 yılı itibariyle kullanımı hızı bir şekilde artmıştır. Ekonomi anahtar kelimesi ise 2011-2013 ve 2014 yıllarında makine öğrenmesi anahtar kelimesinin kullanımı ile aynı sıkıkta iken, yıllar içerisinde kullanımı artmakla birlikte makine öğrenmesi kelimesi kadar hızlı bir artış göstermemiştir. 2018 yılına kadar Ekonometri anahtar kelimesi çalışmalarda birer kez kullanıldığı halde bu yıldan sonra kullanım sıklığının arttığı görülmektedir. Nedensellik anahtar kelimesi 2011 yılında bir kez kullanılmış ve 2017 yılına kadar hiç anahtar kelime olarak kullanılmamıştır. 2017 yılında ise ilk kez finansal ekonometri anahtar kelime olarak kullanılmışır. 2010 yılında anahtar kelime olarak makine öğrenmesi hiç kullanıımamışken, 2014 yııına kadar kullanımı ortaya çıkmış ve bu yıldan sonra da hızla artmıştır. Son iki yılda sosyal medya, duygu analizi, nedensellik, Ekonomi ve Ekonometri ile birlikte kullanımı dikkat çekmektedir. Bu durum, uzun yıllar nedenselliğin makine öğrenmesi içerisinde yer bulamaması nedeniyle konuya uzak duran Ekonomistlerin, son yıllarda tüketicilerin satin alma davranışlarının incelenmesinde makine öğrenmesi tekniklerinden yararlanmakta olduklarının bir göstergesi olarak gösterilebilir. Şekil 2'de özellikle 2018 yılından itibaren nedensellik, büyük veri ve makine öğrenmesi ile Ekonomi ve Ekonometri ilişkisinin kurulmuş olduğu görülmektedir. Aynı zamanda kümelenme yapıları itibariyle veri madenciliği, metin madenciliği, sosyal medya araştırmaları ve sınıflandırma, ekonomi alanında makine öğrenmesi ve algoritma temelinde araştırılmaktadır. Benzer şekilde Ekonometri'de yapay zeka ve tahminleme çalışmaları ile de ilgilenilmekte olduğu sonucuna ulaşılmaktadır.

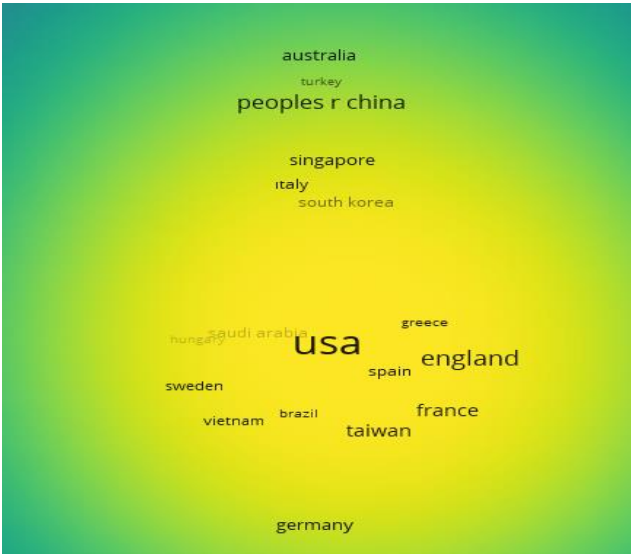

Şekil 3: Yapılan Çalışmaların Ülke Yoğunluğu
Tablo 2: En Çok Yayın Yapan Ülkeler ve Atıf Sayıları

Sıra
\begin{tabular}{|c|c|c|c|}
\hline 1 & Ülke & Yayın Sayısı & Atıf Sayısı \\
\hline 2 & ABD & 137 & 2031 \\
\hline 3 & Ingiltere & 35 & 511 \\
\hline 4 & Almanya & 21 & 296 \\
\hline 5 & italya & 15 & 109 \\
\hline$\vdots$ & $\vdots$ & $\vdots$ & 76 \\
\hline 25 & Türkiye & 4 & $\vdots$ \\
\hline
\end{tabular}

Bilim dallarına sağladığı katkı bakımından ülkelerin durumu incelendiğinde (Tablo 2) bu konuda yayın yapılan 53 ülke arasından, en fazla yayın yapan ve çalışmaları en fazla atıf alan ülkenin ABD olduğu ve ikinci sırada yer alan İngiltere'nin yaklaşık 4 katı çalışmaya sahip olduğu görülmektedir. Ülkelerin atıf ilişkileri bakımından yoğunluk grafiği (Şekil 3) incelendiğinde yayın sayısı daha fazla olan İngiltere'nin ABD ile birlikte bir küme oluşturduğu; Almanya'nın kurulan ağ bağlantıları neticesinde bu kümeye görece yakın olduğu; İtalya ve Avustralya'nın Çin Halk Cumhuriyeti ile birlikte bir küme oluşturduğu; ülkeler arasında 25. sırada olan 
Türkiye'nin ise bu küme içerisinde olduğu görülmektedir. Singapur ve Yeni Zelanda'nın az sayıda çalışmaya sahip olmalarına karşın atıf sayılarının yüksek olması dikkat çekmektedir.

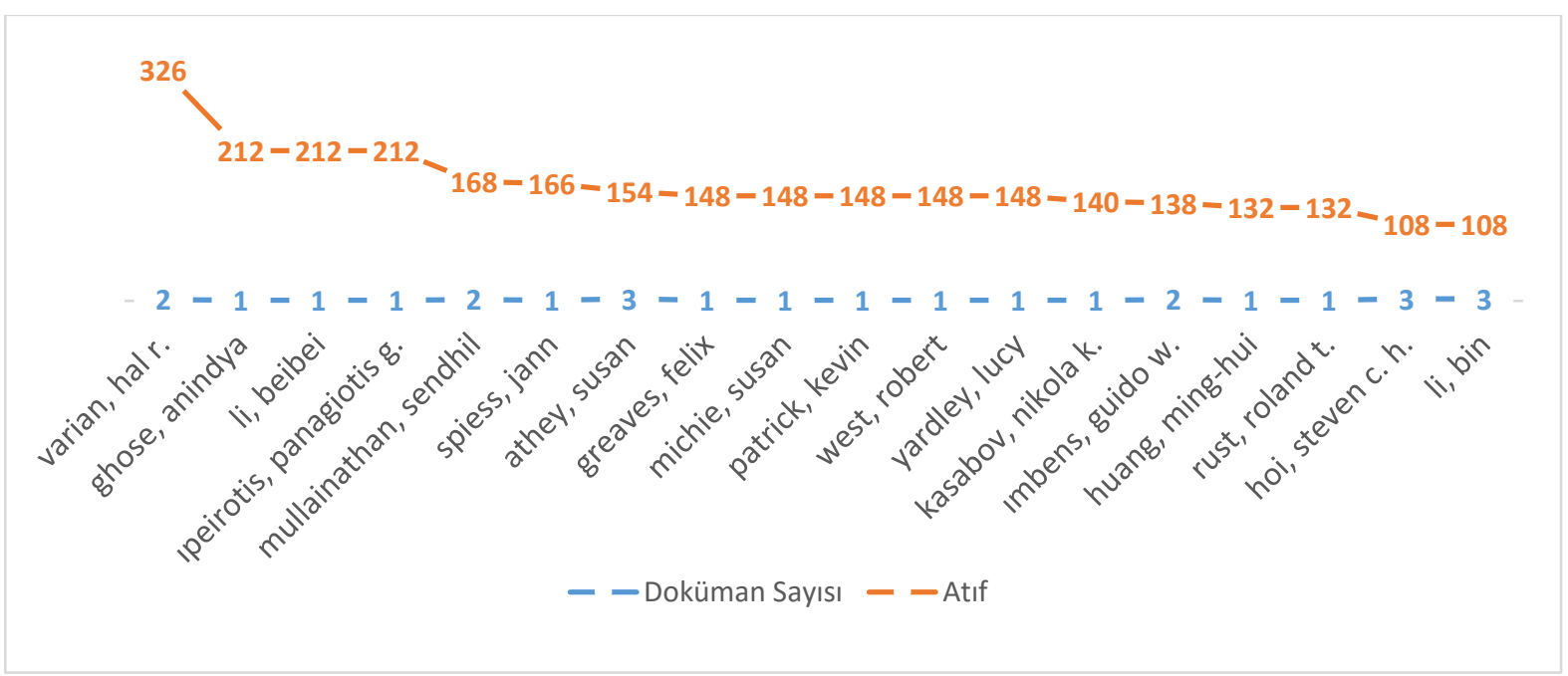

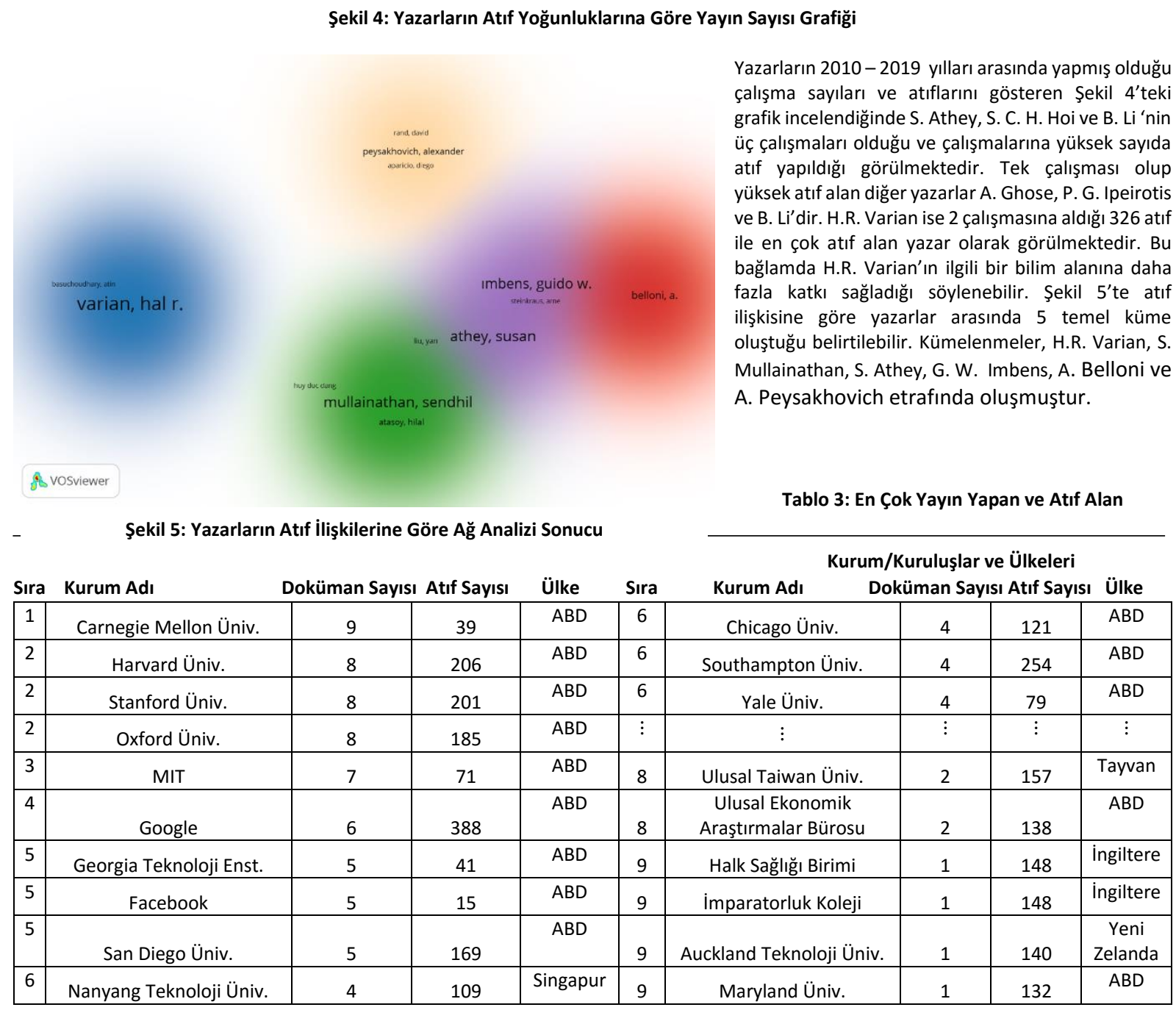




\begin{tabular}{|c|c|c|c|c|c|c|c|c|c|}
\hline 6 & NYU & 4 & 222 & ABD & $\vdots$ & $\vdots$ & $\vdots$ & $\vdots$ & $\vdots$ \\
\hline 6 & UCL & 4 & 225 & İngiltere & 8 & İzmir Katip Çelebi Üniv. & 2 & 3 & Türkiye \\
\hline 6 & Berkeley Üniv. & 4 & 306 & ABD & 9 & Van Yüzüncü Yıl Üniv. & 1 & 0 & Türkiye \\
\hline
\end{tabular}

Son on yıl içerisinde çalışma yapan 458 kurum veya üniversite olduğu görülmektedir. Tablo 3 incelendiğinde doküman sayısı olarak en çok çalışma yapan üniversitenin Carnegie Mellon Üniversitesi olduğu ancak doküman sayısına göre atıf sayısının az olduğu tespit edilmektedir. Carnegie Mellon Üniversitesi'ni Harvard, Standford ve Oxford Üniversiteleri izlemektedir. Google şirketi tarafından yapılan 6 çalışma 388 atıf ile en çok atıf alan kurum olmaktadır. Google'ı atıf sayısının çokluğu ile Berkeley Üniversitesi ve Southampton Üniversitesi izlemektedir. Yayın sayısı ve atıf sayısı bakımından ülkeler incelendiğinde yine ABD’nin ilk sırada yer aldığı görülmektedir. Listede iki Türk Üniversitesinin de olduğu görülmektedir. Ön sırayı alan kurumların ABD'de olması dikkat çekmektedir.

Tablo 4: 2010 - 2015 ve 2016 - 2019 Dönemlerinde En Çok Yayın Yapan Dergi Sıralaması

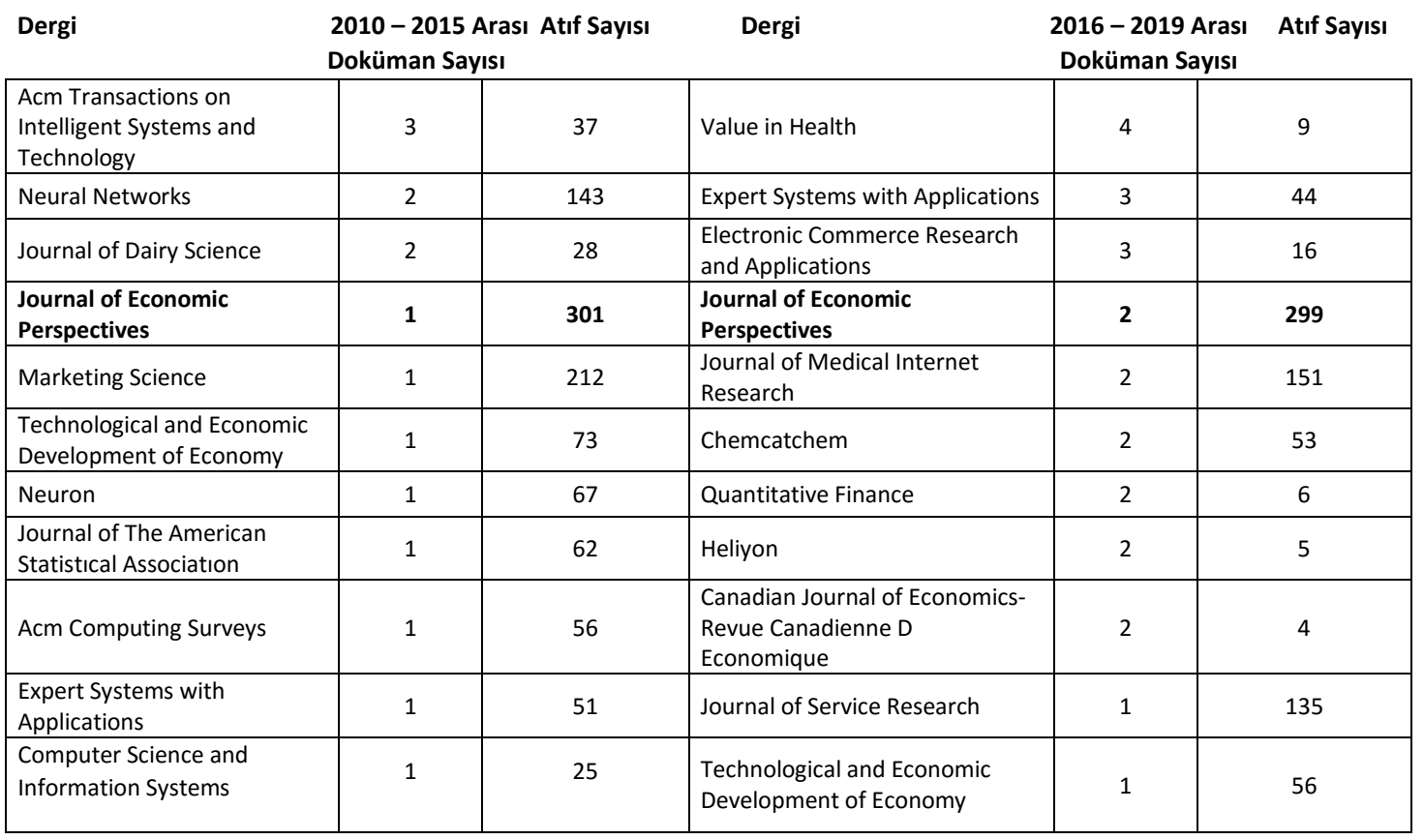

Çalışmaların yayınlandığı kaynaklar 5'er yıllık iki döneme ayrılarak karşılaştırılmış ve sonuçlar Tablo 4'te verilmiştir. Buna göre, her iki dönemde de ortak olarak yayın çıkartan derginin Journal of Economic Perspectives olduğu gözlemlenmektedir. Bu dergide yayımlanan çalışma sayısı görece az olsa da yayınlara yapılan atıf sayısı yüksektir. Bu da yayınların kalitesinin bir ölçüsü olarak görülebilmektedir. Aynı zamanda, bu derginin ilgili konuda gelişen çalışmaları yayınladığı söylenebilir.

\section{SONUÇ}

Astronomi, biyoloji ve genetik alanında yaygın olarak kullanılan büyük verinin günümüzde başta finans ve bankacılık sektörü olmak üzere, sağlık sektörü, pazarlama, yapay zeka ve tahmin konusunda çalışmaların ilerlemesi ile birçok farklı alanda belirleyici bir rol oynamaya başladığı görülmektedir (Çağlayan Akay, 2018). Son yıllara kadar bu alanda yapılan çalışmalarda nedensellik ilkesinin algoritmalarda yer bulamaması nedeniyle ekonomistler makine öğrenmesi ve büyük veri kavramlarına uzak durmuşlardır. Ancak son yıllarda Ekonomi konulu dergilerin de makine öğrenmesi çalışmalarına yer verdiği söylenebilir. Çalışmada 2010 - 2019 yılları arasında Ekonomi ve Makine öğrenmesi ile Ekonometri ve Makine öğrenmesi konularında yapılan 311 çalışma incelenmiştir. Bibliyometrik Analiz sonucunda, yıllar bazında çalışmalarda meydana gelen değişimler, ilgili konu hakkında en çok yayın yapan yazar veya en fazla atıf alan çalışmalar, bu çalışmaların ülkeler ve kurumlara göre dağılımı, çalışmalarda en sık kullanılan dil, çalışma konusunun seyri ve anahtar kelimelerdeki ilişkisel oluşumdaki ilerlemeler gibi değişkenler temelinde bulgular elde edilmiştir. Ayrıca Sosyal Ağ Analizi ile birbirleriyle ağ yapısı oluşturan (karşılıklı etkileşim içinde olan) yazarlar, ülkeler ve anahtar kelimeler arasındaki kümelenmeler ve ilişkiler haritalandırılmıştır. Son dönemlerde çalışma sayısının artmasıyla birlikte özellikle 2018 yılından itibaren nedensellik, büyük veri ve makine öğrenmesi ile Ekonomi ve Ekonometri ilişkisinin kurulduğu bulgusuna ulaşılmıştır. Veri madenciliği, metin madenciliği, sosyal medya araştırmaları ve sınıflandırma konuları, Ekonomi alanında makine öğrenmesi ile ilişkili bulunmuştur. Benzer şekilde, Ekonometri alanında makine öğrenmesi çalışmalarının yapay zeka ve tahminleme çalışmaları ile ilişkili olduğu sonucuna ulaşılmıştır. Bulgular incelendiğinde, bu konular üzerine her yıl en fazla çalışmanın Amerika Birleşik Devletleri'nde (ABD) yapıldığı, en çok atıf alan çalışmanın Varian (2014) olduğu belirlenmiştir. Aynı zamanda, son on yıldaki çalışmalar değerlendirildiğinde, Ekonomi ve Ekonometri'de günümüzde dikkat çeken Makine öğrenmesi konularına yönelimin hızla artmış olduğu, çalışmaların "nedensellik" ve "nedensel etki" anahtar kelimelerinin yanısıra "Finansal Ekonometri", "Davranışsal Ekonomi", "Deneysel Ekonomi" ile de ilişkilendirildiği ve 
finans ile bağlantılı anahtar kelimelerin sıklıkla kullanıldığı gözlemlenmiştir. Sonuçta elde edilen bulgular Makine Öğrenmesi'nin Ekonomi ve Ekonometri alanlarındaki gelişimine ışık tutar niteliktedir.

\section{KAYNAKÇA}

Al, U., (2008). Türkiye'nin Bilimsel Yayın Politikası: Atıf Dizinlerine Dayalı Bibliyometrik Bir Yaklaşım, Doktora Tezi, Hacettepe Üniversitesi Sosyal Bilimler Enstitüsü.

Alonso, J. M., Castiello, C., Mencar, C., (2018). A Bibliometric Analysis of the Explainable Artificial Intelligence Research Field, Communications in Computer and Information Science book series (CCIS, volume 853).

Ardito, L., Scuotto, V., Del Giudice, M. and Petruzzelli, A.M. (2019). A bibliometric analysis of research on Big Data analytics for business and management, Management Decision, Vol. 57 No. 8, pp. 1993-2009. https://doi.org/10.1108/MD-07-2018-0754.

Basaglia, T., (2014), What Is Bibliometrics And Why We Should Care About It?, CERN Library, 2014, http://Slideplayer.Com/Slide/6213346/

Belmonte, J.L., Segura Robles, A., Moreno Guerrero, A.J., Parra Gonzalez, M.E. (2020). Machine Learning and Big Data in the Impact Literature. A Bibliometric Review with Scientific Mapping in Web of Science. Symmetry, 12(495): 1-15.

Bhattacharya, Sujit., (2019). Some Salient Aspects of Machine Learning Research: A Bibliometric Analysis, Journal of Scientometric Res, $8(2 s): 85-92$.

Çağlayan Akay, E. (2020). Ekonometride Büyük Veri ve Makine Öğrenmesi: Temel Kavramlar, Der Yayınları, İstanbul.

Çağlayan Akay, E. (2018). Ekonometride Yeni Bir Ufuk: Büyük Veri ve Makine Öğrenmesi. Social Sciences Research Journal, 7(2): $41-53$.

dos Santos, B.S., Steiner, M.T., Fenerich, A.T., Lima, R.H., (2019), Data mining and machine learning techniques applied to public health problems: A bibliometric analysis from 2009 to 2018. Comput. Ind. Eng, 138, 106120.

Gürsakal, N. (2018). Makine Öğrenmesi. 1.Baskı, Bursa: Dora Basım Yayın Dağıtım Ltd.Şti.

Kocarık, B. (2018). Büyük Veri Üzerine Uluslararası Listeratürün Bibliyometrik Analizi. Marmara Üniversitesi, SBE, Ekonometri Anabilim Dalı, İstatistik Bilim Dalı, Yayımlanmamış Yüksek Lisans Tezi.

Li, Y., Xu, Z., Wang X., Wang X., (2020). A bibliometric analysis on deep learning during 2007-2019, International Journal of Machine Learning and Cybernetics, Springer-Verlag GmbH Germany, part of Springer Nature 2020, https://doi.org/10.1007/s13042-020-01152-0.

Liao, H., Tang, M., Luo, L., Li, C., Chiclana F. and Zeng, X.-J., (2018). A Bibliometric Analysis and Visualization of Medical Big Data Research, Sustainability, 10(12), 4851.

Liu, X., Sun, R., Wang, S., Wu, Y. J., (2019). The Research Landscape of Big Data: A Bibliometric Analysis, Discover Journal, ISSN: 0737-8831.

Makawana, P. R., Jhaveri, R. H., (2017). A Bibliometric Analysis of Recent Research on Machine Learning for Cyber Security, Lecture Notes in Networks and Systems book series (LNNS, volume 19).

Mishra, D., Gunasekaran, A., Papadopoulos, T. et al. (2018). Big Data and supply chain management: a review and bibliometric analysis. Ann Oper Res 270, 313-336. https://doi.org/10.1007/s10479-016-2236-y.

Nicholas, D. and Ritchie, M., (1978). Literature and Bibliometrics London: Clive Bingley.

Rialti, R., Marzi, G., Ciappei, C., Busso, D., (2019). Big Data And Dynamic Capabilities: A Bibliometric Analysis and Systematic Literature Review, Discover Journal, ISSN: 0025-1747.

Salod Z., Singh Y., (2020). A five-year (2015 to 2019) analysis of studies focused on breast cancer prediction using machine learning: A systematic review and bibliometric analysis, Systematic Reviews and Meta-Analysis, Department of TeleHealth, University of KwaZulu-Natal, Durban, South Africa.

Stout, N.L., Alfano, C.M., Belter, C., W., Nitkin, R., Cernich, A., Siegel, K. L., Chan, L., (2018). A Bibliometric Analysis of the Landscape of Cancer Rehabilitation Research (1992-2016), JNCI J Natl Cancer Inst, 110(8), doi: 10.1093/jnci/djy108.

Pritchard, A., (1969). Statistical Bibliography Or Bibliometrics? Journal Of Documentation, 25 (4): 348-349.

Toroczkai, Z., (2005). Complex Networks The Challenge of Interaction Topology, Los Alamos Science Number 29.

Xian H., Madhavan, K., (2014). Anatomy of Scholarly Collaboration in Engineering Education: A Big-Data Bibliometric Analysis. The Research Journal for Engineering Education, https://doi.org/10.1002/jee.20052.

Wang K., Feng C., Li M., Pei, Q., Li, Y., Zhu, H., Song, X., Pei H. and Tan, F., (2020). A bibliometric analysis of 23,492 publications on rectal cancer by machine learning: basic medical research is needed, Therapeutic Advances in Gastroenterology, Vol. 13: 1-11.

Yilmazel, Ö., (2019). Yök Ulusal Tez Merkezı’nde Büyük Veri Alanında Kayıtlı Bulunan Lisansüstü Tezlerinin Analizi, Karadeniz Uluslararası Bilimsel Dergi, Issue No: 41, pp. 225-240. 